\title{
Infestação por larvas de Cerotoma arcuata (Olivier) (Coleoptera: Chrysomelidae) em nódulos de feijoeiro em cultivo com cobertura morta ou em consórcio com milho ou com caupi
}

\author{
Infestation by Cerotoma arcuata (Olivier) (Coleoptera: Chrysomelidae) larvae on Phaseolus bean with \\ mulching or intercropped with maize or cowpea
}

\author{
Maria Lucia França TeixeiraI Avílio Antonio Franco ${ }^{I I}$
}

\section{RESUMO}

A vaquinha Cerotoma arcuata ataca folhas de leguminosas e suas larvas alimentam-se de raízes e também de nódulos, onde a fixação de nitrogênio (FBN) ocorre. O ataque das larvas aos nódulos pode causar mais danos à cultura do feijoeiro do que o consumo das folhas pelas formas adultas. Este estudo foi conduzido em condições de campo para avaliar os efeitos da infestação de C. arcuata no cultivo do feijoeiro com ou sem cobertura morta ou consorciado com caupi ou com milho. A nodulação, o crescimento e a produção de grãos de feijoeiro quando consorciado com caupi não diferiram do controle. A barreira aos insetos formada pelo milho adensado falhou, provavelmente devido à infestação precoce de $\mathbf{C}$. arcuata e ao sombreamento causado pelo milho, com redução na produtividade de feijoeiro. O consumo dos nódulos pelas larvas na cultura de feijão solteiro e nos consórcios foi superior ao do tratamento com cobertura morta. A barreira física imposta pela cobertura morta agiu provavelmente através da redução da oviposição diretamente no solo e do ressecamento dos ovos sobre a palha e resultou em menor porcentagem de nódulos furados, com conseqüente aumento no número e peso de nódulos, no peso de raiz e na produção de grãos. Os consórcios com milho ou com caupi não reduziram a infestação de feijoeiro por $\boldsymbol{C}$. arcuata, mas a aplicação da cobertura morta antes da infestação reduziu os danos causados pelas larvas aos nódulos e favoreceu a FBN e a produtividade

Palavras-chave: vaquinha, Phaseolus vulgaris, Zea mays, Vigna unguiculata, nodulação.

\section{ABSTRACT}

The bean leaf beetle Cerotoma arcuata is a legume leaf eater and its larvae feed on roots and also nodules where nitrogen fixation occurs. The attack of larvae to nodule may result in more damage to the bean crop than the consumption of leaves by adults. This study was conducted under field conditions to test the effects of C. arcuata infestation on Phaseolus bean with or without straw mulching or intercropped with maize or cowpea. Nodulation, growth and grain production when intercropping with cowpea did not differ from the control. The insect barrier formed by the maize's high density failed, probably due to the early infestation by $\mathrm{C}$. arcuata, as well as shading by the rows of maize, thereby reducing grain yield. Consumption of nodules was higher on the Phaseolus bean with or without intercropping than on the treatment with straw mulching. The physical barrier imposed by straw mulch probably acted by reducing oviposition directly on soil and drying the eggs laid above the straw, resulting in a smaller percentage of punctured nodules and consequently increasing nodule number and dry weight, root dry weight and grain yields. Intercropping with maize and cowpea did not reduce Phaseolus bean infestation by C. arcuata but straw mulching applied before infestation reduced damage caused by larvae to the nodules, increasing $\mathrm{N}_{2}$ fixation and grain yields.

Key words: Bean leaf beetle, Phaseolus vulgaris, Zea mays, Vigna unguiculata, nodulation.

\section{INTRODUÇÃO}

Cerotoma arcuata é conhecido, da mesma forma que outros crisomelídeos, como "vaquinha” por desfolhar feijão (Phaseolus vulgaris L.), soja (Glycine $\max \left(L_{.}\right)$Merril), caupi (Vigna unguiculata (L.) Walp.) e outras leguminosas. Como o desfolhamento e a transmissão de vírus são reconhecidamente causados pelo inseto adulto, pouca importância é dada à fase larval. Entretanto, as larvas também transmitem vírus (SALAS et al., 1999) e, ao se alimentarem de plântulas, coletos, cotilédones, raízes e principalmente de nódulos de feijoeiro, onde ocorre a fixação biológica de nitrogênio (FBN), podem reduzir em 25 e $45 \%$ a produção de grãos de feijoeiro dependente de

\footnotetext{
ILaboratório de Fitossanidade, Instituto de Pesquisas Jardim Botânico do Rio de Janeiro (JBRJ), 22460-000, Rio de Janeiro, RJ, Brasil. E-mail: malu@jbrj.gov.br. Autor para correspondência.

IILaboratório de Leguminosas, Embrapa Agrobiologia, Seropédica, RJ, Brasil.
} 
nitrogênio via simbiose, com rizóbio em condições de campo (TEIXEIRA, 1993) e de casa-de-vegetação (TEIXEIRA et al., 1996), respectivamente. O feijoeiro, quando bem nodulado e em condições favoráveis, pode suprir o fornecimento de nitrogênio através da simbiose com rizóbio e alcançar níveis de produtividade em condições de campo de até $2.500 \mathrm{~kg} \mathrm{ha}^{-1}$ (STRALIOTTO et al., 2003).

Sendo insetos de solo com habilidade restrita de locomoção, o acesso das larvas às raízes pode ser problemático. Em lavoura de soja, onde a destruição de nódulos por larvas de Cerotoma trifurcata Forster pode reduzir a capacidade de fixação de nitrogênio em até 45\% (LAYTON, 1983), TROXCLAIR \& BOETHEL (1984) verificaram a preferência para postura de $\boldsymbol{C}$. trifurcata em sistema de plantio convencional e maior mortalidade de ovos e larvas em sistema de plantio direto sobre palha de trigo (Triticum sp.). A cobertura morta, agindo principalmente como uma barreira física, poderia contribuir para a redução na quantidade de larvas de C. arcuata que alcançam o sistema radicular do feijoeiro. O uso da cobertura morta traz ainda benefícios intrínsecos como: o favorecimento da infiltração de água, da atividade biológica, da fertilidade do solo, a prevenção da erosão, a diminuição da poeira e de infestação por ervas daninhas, a modificação do microclima, podendo ainda servir de abrigo aos insetos benéficos (ALTIERI et al., 2003). A mortalidade de ovos e larvas de Leptinotarsa decemlineata (Say) (Coleoptera: Chrysomelidae) aumentou após a colocação de cobertura de palha de trigo em cultura de batata (Solanum tuberosum L.), devido ao incremento do número de insetos predadores de solo, resultando em ganhos de até 35\% no rendimento da cultura (BRUST, 1994). Resultados semelhantes foram obtidos por JOHNSON et al. (2004) através de armadilhas de solo do tipo "pitfall", que registraram em batata com cobertura de palha um alto número de insetos predadores, responsáveis pela redução do número de ovos e larvas de $\mathbf{L}$. decemlineata em relação ao controle.

O enriquecimento dos ecossistemas agrícolas através do consórcio ou da manutenção de reservas de vegetação diversificada pode reduzir a incidência de vários insetos fitófagos, devido à dificuldade encontrada por eles em encontrar seus hospedeiros, às mudanças no microclima da cultura e ao incremento das populações de inimigos naturais (ALTIERI et al., 2003). A maior diversidade de insetos herbívoros e de outras fontes alimentares como néctar e pólen, bem como a existência de melhores condições de abrigos, de microclima, de dispersão e reprodução, são alguns fatores relacionados aos efeitos do consórcio sobre a população de inimigos naturais (ANDOW, 1991). Foi observado que a incidência de Cerotoma sp. em monocultura de feijão é maior do que em cultivo misto com milho (Zea mays L.) (BASTOS et al., 2003) e a incidência de insetos predadores e aracnídeos é maior no sistema consorciado (MILANEZ, 1987). Insetos predadores também causaram maior impacto na população do besouro do feijão (Epilachna varivestis Mulsant) (Coleoptera: Coccinelidae), em feijoeiro, quando consorciado com milho do que em monocultura(COLL \& BOTTRELL, 1995). RISH (1980) estudou a dinâmica populacional dos crisomelídeos Cerotoma ruficornis rogersi Jacoby, Diabrotica viridula F. e Acalymma thiemei Baly em feijão, milho e abóbora (Cucumis sp.), em cultivos simples e consorciados. Cada espécie esteve em maior número na monocultura do que no consórcio, quando este contou com pelo menos uma planta não hospedeira. A população de $\boldsymbol{E}$. varivestis em feijoeiro solteiro foi maior do que em consórcio com plantas não hospedeiras, que inibiram a imigração do besouro e favoreceram a emigração. Os insetos benéficos predaram mais ovos da praga nos ambientes diversificados do que na monocultura. Entretanto, a interferência causada pelas plantas não-hospedeiras teve maior influência nas populações das pragas do que a mortalidade causada pelos inimigos naturais (ANDOW, 1990).

Cerotoma tingomarianus Bechyné foi considerada uma das cinco pragas mais importantes para a cultura do caupi no Estado do Acre (FAZOLIN, 1995) e C. arcuata é citado por QUINTELA et al. (1991) como uma das doze principais pragas do caupi no Brasil. FAZOLIN \& GOMES (1993) verificaram a preferência alimentar de $\boldsymbol{C}$. tingomarianus por caupi em detrimento ao kudzu (Pueraria thunbergiana (Sieb. \& Zucc.) Benth.), uma leguminosa considerada como hospedeiro alternativo. Variedades precoces de soja são utilizadas com sucesso como cultura armadilha para o controle de $\boldsymbol{C}$. trifurcata se semeadas previamente, em local próximo ao plantio principal de soja (HOKKANEN, 1991). Estudos de laboratório e de campo verificaram a preferência alimentar de $\boldsymbol{C}$. ruficornis rogersi por várias cultivares de caupi em detrimento do feijoeiro (RISCH, 1976), podendo o cultivo múltiplo com o caupi, hospedeiro para Cerotoma sp., ser explorado visando à redução dos danos em feijoeiro.

O objetivo deste trabalho foi estudar os danos causados pela infestação de $\boldsymbol{C}$. arcuata à nodulação, ao crescimento e ao rendimento de feijoeiro 
solteiro, consorciado com planta hospedeira (caupi), ou não-hospedeira, (milho), visando a atrair ou dispersar os adultos de $\boldsymbol{C}$. arcuata, respectivamente, e com aplicação de cobertura morta, utilizada como barreira física para ovos e larvas.

\section{MATERIAL E MÉTODOS}

Em área de campo experimental da EmbrapaAgrobiologia, Seropédica, RJ, reconhecida pela ocorrência de $\boldsymbol{C}$. arcuata em cultivos de feijoeiro anteriores, foi conduzido um experimento em solo Argissolo vermelho-amarelo, com as seguintes características de fertilidade: $\mathrm{pH}$ em água 5,$5 ; 2,7 \mathrm{mmol}$ $\mathrm{dm}^{-3}$ de Ca+Mg; 15,2g dm ${ }^{-3}$ de P e 36,5g dm ${ }^{-3}$ de K. O solo foi corrigido com uma tonelada de calcário ha ${ }^{-1} \mathrm{e}$ adubado no sulco, no plantio com $90 \mathrm{~kg}$ de $\mathrm{P}_{2} \mathrm{O}_{5} \mathrm{ha}^{-1}$, $40 \mathrm{~kg}$ de $\mathrm{K}_{2} \mathrm{O}$ ha $^{-1}$, e $30 \mathrm{~kg}$ de micronutrientes ha- ${ }^{-1} \mathrm{O}$ milho, em consórcio com feijoeiro, recebeu $80 \mathrm{~kg}$ de $\mathrm{N}$ ha $^{-1}$ em cobertura, aplicando-se $1 / 3$ no plantio e $2 / 3$ aos 40 dias após a emergência (DAE).

Foram usados os seguintes tratamentos com feijoeiro: solteiro, solteiro com cobertura morta, consorciado com caupi e consorciado com milho. Foram realizadas quatro coletas: aos 20, 27, 34, e 43 DAE. As sementes de feijão, cultivar "Carioca 80" e as de caupi, cultivar “CNC 0434”, foram plantadas em março de 1995, numa densidade de 15 sementes $\mathrm{m}^{-1}$ linear. Na ocasião da semeadura, receberam inoculantes em turfa contendo as estirpes de rizóbio: CIAT 899 (SEMIA 4077), oficialmente recomendada para feijão, e BR 2001 para caupi. O milho, cultivar “AG 405”, foi semeado simultaneamente ao feijão, numa densidade de 15 sementes $\mathrm{m}^{-1}$ linear.

O delineamento experimental foi em blocos ao acaso com quatro repetições. Cada parcela foi formada por oito linhas e ocupou uma área de $28 \mathrm{~m}^{2}(7 \mathrm{x} 4 \mathrm{~m})$. Duas linhas centrais foram reservadas para a produção de grãos, duas linhas externas foram destinadas à bordadura e as linhas restantes para as coletas realizadas durante o experimento para avaliação da nodulação, com espaçamento de $0,5 \mathrm{~m}$ entre linhas e de dois metros entre parcelas. Foi semeada com antecedência de 30 dias uma bordadura de duas linhas de caupi em torno do experimento para atrair um maior número de insetos e o plantio de uma linha adensada de milho teve como objetivo dificultar o acesso dos insetos de uma parcela para a outra.

A temperatura média foi de $22,6^{\circ} \mathrm{C}$, a umidade relativa média foi de $68,6 \%$, a precipitação pluviométrica foi de $147 \mathrm{~mm}$, suplementada pela irrigação por aspersão. O tratamento com cobertura morta recebeu uma camada de grama batatais (Paspalum notatum), cortada com antecedência de 30 dias, com aproximadamente $2 \mathrm{~cm}$ de espessura, pesando 2,53ton ha $^{-1}$, aplicada superficialmente após a emergência das sementes.

A infestação de $\boldsymbol{C}$. arcuata se deu de forma natural e foi amostrada por meio de captura dos insetos com rede entomológica de $30 \mathrm{~cm}$ de diâmetro (FAZOLIN \& GOMES, 1993) e contagem dos mesmos, percorrendo-se todas as plantas de uma das duas linhas centrais de cada parcela.

A atividade da nitrogenase foi avaliada pelo método da redução de acetileno (HARDY et al., 1968) e o nitrogênio acumulado na parte aérea pelo método semi-micro Kjedahl (BREMNER, 1965). Aos 70 DAE, foi avaliada a produtividade de grãos.

Os dados de número de nódulos e porcentagem de nódulos furados foram respectivamente transformados para $\sqrt{\mathrm{x}+1}$ e arc sen $\sqrt{\mathrm{x} 100^{-1}}$ antes da análise estatística. A análise estatística constou de análise de variância seguida de comparação de médias pelo Teste de Duncan adotando 5\% de probabilidade de erro.

\section{RESULTADOS E DISCUSSÃO}

A semeadura de feijão consorciado com milho ou com caupi não evitou a infestação de larvas de $\boldsymbol{C}$. arcuata aos nódulos de feijoeiro, já que, aos 20 DAE, os danos causados à nodulação nos consórcios não diferiram aos do feijão solteiro (Tabela 1). TELLEZROBLETO \& MAES (1991) observaram um efeito benéfico do consórcio de feijão com milho no controle de Cerotoma atrofasciata Jacoby. Uma vez que $\boldsymbol{C}$. arcuata não ataca o milho e voa normalmente abaixo de $70 \mathrm{~cm}$ de altura, como não tem sido observada correlação positiva entre a altura do vôo e a das plantas (YEPEZ-GIL \& AQUILES-MONTAGNE, 1990), esperava-se que o plantio adensado do milho agisse como uma barreira física, diminuindo o fluxo do inseto da monocultura para o consórcio (RISH, 1980). Isto não ocorreu devido ao plantio simultâneo com o feijão, mais utilizado pelos agricultores, aliado à infestação precoce de $\boldsymbol{C}$. arcuata, que começou na emergência das culturas e atingiu seu pico aos 34 DAE com seis insetos por planta (Tabela 1), ficando acima do nível de dano (CARDONA et al., 1982). Em consórcio milho e caupi, onde a maior incidência de $\boldsymbol{C}$. arcuata deu-se dos 61 aos 68 DAP, a barreira formada pelo milho foi eficiente em restringir a dispersão e a reprodução do inseto (AZEVEDO \& ARAÚJO, 2000). C. arcuata não evitou o consumo de folhas de feijoeiro sombreado pelo milho como observado por RISH (1980), mas o sombreamento pode ter prejudicado a produção de 
Tabela 1 - Média e erro-padrão das variáveis: número de adultos de $\boldsymbol{C}$. arcuata, atividade da nitrogenase, matéria seca de nódulos, número de nódulos e porcentagem de nódulos furados de feijoeiro solteiro, com cobertura morta ou em consórcio com caupi ou milho, colhido aos 20, 27, 34 e 43 DAE $(n=4)$.

\begin{tabular}{|c|c|c|c|c|c|}
\hline \multirow{2}{*}{ Tratamentos } & $\begin{array}{l}\text { Insetos } \\
\text { adultos }{ }^{1}\end{array}$ & $\begin{array}{l}\text { Atividade da } \\
\text { nitrogenase }^{1}\end{array}$ & $\begin{array}{c}\text { Matéria seca de } \\
\text { nódulos }^{1}\end{array}$ & Nódulos ${ }^{1}$ & $\begin{array}{l}\text { Nódulos } \\
\text { furados }{ }^{1}\end{array}$ \\
\hline & $\mathrm{n}^{0} \mathrm{pl}^{-1}$ & $\mu \mathrm{molC}_{2} \mathrm{H}_{4} \mathrm{pl} \mathrm{h}^{-1}$ & $\mathrm{mg} \mathrm{pl}^{-1}$ & $\mathrm{n}^{0} \mathrm{pl}^{-1}$ & $\% \mathrm{pl}^{-1}$ \\
\hline Coleta & \multicolumn{5}{|c|}{$20 \mathrm{DAE}$} \\
\hline Feijão solteiro & $2 \pm 0,79 \mathrm{a}$ & $4,0 \pm 1,78 \mathrm{a}$ & $20 \pm 9,96 \mathrm{a}$ & $30 \pm 6,83 b$ & $80 \pm 4,56 a$ \\
\hline Cobertura morta & $3 \pm 0,35 a$ & $8,8 \pm 2,05 a$ & $32 \pm 8,09 a$ & $119 \pm 31,83 a$ & $7 \pm 1,99 b$ \\
\hline Caupi consorciado & $2 \pm 0,35 a$ & $5,3 \pm 1,55 a$ & $22 \pm 5,78 a$ & $29 \pm 1,02 b$ & $68 \pm 15,89 a$ \\
\hline Milho consorciado & $2 \pm 0,7 \mathrm{a}$ & $2,7 \pm 0,70 a$ & $13 \pm 3,08 \mathrm{a}$ & $26 \pm 3,36 b$ & $62 \pm 30,89 a$ \\
\hline Média & $2 \pm 0,15$ & $5,2 \pm 0,45$ & $22 \pm 1,61$ & $51 \pm 4,92$ & $54 \pm 2,30$ \\
\hline CV (\%) & 20,87 & 31,23 & 30,39 & 27,97 & 31,04 \\
\hline Coleta & \multicolumn{5}{|c|}{$27 \mathrm{DAE}$} \\
\hline Feijão solteiro & $4 \pm 0,61 \mathrm{a}$ & $0,2 \pm 0,04 b$ & $2 \pm 0,81 b$ & $12 \pm 3,83 b$ & $70 \pm 7,14 \mathrm{a}$ \\
\hline Cobertura morta & $4 \pm 0,5 \mathrm{a}$ & $26,4 \pm 15,62 \mathrm{a}$ & $41 \pm 14,64 \mathrm{a}$ & $90 \pm 23,49 \mathrm{a}$ & $12 \pm 4,75 b$ \\
\hline Caupi consorciado & $5 \pm 0,35$ a & $3,5 \pm 1,75 b$ & $8 \pm 2,68 b$ & $20 \pm 1,74 b$ & $59 \pm 7,52 \mathrm{a}$ \\
\hline Milho consorciado & $4 \pm 0,61 \mathrm{a}$ & $1,5 \pm 0,85 b$ & $7 \pm 3,57 b$ & $18 \pm 3,06 b$ & $63 \pm 2,77 a$ \\
\hline Média & $4 \pm 0,15$ & $7,8 \pm 2,19$ & $14 \pm 1,97$ & $35 \pm 3,43$ & $51 \pm 1,59$ \\
\hline CV (\%) & 12,68 & 67,30 & $42, \overline{23}$ & 30,45 & 20,63 \\
\hline Coleta & \multicolumn{5}{|c|}{$34 \mathrm{DAE}$} \\
\hline Feijão solteiro & $6 \pm 0,61 \mathrm{a}$ & $1,1 \pm 0,83 \mathrm{a}$ & $7 \pm 2,37 b$ & $18 \pm 4,74 b$ & $58 \pm 4,61 \mathrm{a}$ \\
\hline Cobertura morta & $5 \pm 0,79 a$ & $9,6 \pm 4,03 \mathrm{a}$ & $46 \pm 10,82 a$ & $90 \pm 16,78 \mathrm{a}$ & $14 \pm 1,12 b$ \\
\hline Caupi consorciado & $5 \pm 1,27 \mathrm{a}$ & $4,6 \pm 1,52 \mathrm{a}$ & $18 \pm 11,59 b$ & $32 \pm 5,82 b$ & $38 \pm 8,99 a b$ \\
\hline Milho consorciado & $4 \pm 1,27 \mathrm{a}$ & $3,4 \pm 1,80 a$ & $7 \pm 9,56 b$ & $17 \pm 5,03 b$ & $61 \pm 12,90 a$ \\
\hline Média & $5 \pm 0,30$ & $4,66 \pm 0,64$ & $19 \pm 1,68$ & $39 \pm 2,69$ & $43 \pm 2,01$ \\
\hline CV (\%) & 22,25 & 45,97 & 31,36 & 28,29 & 30,42 \\
\hline Coleta & \multicolumn{5}{|c|}{$43 \mathrm{DAE}$} \\
\hline Feijão solteiro & $6 \pm 0,7 \mathrm{a}$ & $0,2 \pm 0,20 \mathrm{a}$ & $1 \pm 0,32 b$ & $5 \pm 1,5 \mathrm{a}$ & $66 \pm 12,94 \mathrm{ab}$ \\
\hline Cobertura morta & $4 \pm 1,27 \mathrm{a}$ & $0,5 \pm 0,13 \mathrm{a}$ & $5 \pm 1,83 \mathrm{a}$ & $13 \pm 4,15 \mathrm{a}$ & $34 \pm 0,69 b$ \\
\hline Caupi consorciado & $4 \pm 1,45 \mathrm{a}$ & $1,4 \pm 0,99 a$ & $4 \pm 1,59 \mathrm{ab}$ & $16 \pm 4,06 \mathrm{a}$ & $73 \pm 16,21 \mathrm{a}$ \\
\hline Milho consorciado & $3 \pm 0,79 a$ & $0 \mathrm{a}$ & $1 \pm 0,2 b$ & $8 \pm 3,72 \mathrm{a}$ & $85 \pm 7,86 a$ \\
\hline Média & $4 \pm 0,35$ & $0,5 \pm 0,14$ & $3 \pm 0,28$ & $10 \pm 0,95$ & $64 \pm 2,54$ \\
\hline CV (\%) & 27,62 & 29,02 & 30,51 & 37,21 & 30,01 \\
\hline
\end{tabular}

${ }^{1}$ Valores na mesma coluna para cada coleta, não seguidos pela mesma letra, diferem entre si pelo teste de Duncan em nível de $5 \%$ de probabilidade de erro.

grãos (Tabela 2), já que esta tende a aumentar com o incremento da densidade de semeadura da leguminosa e a diminuir com o incremento da densidade de semeadura do milho (RAMALHO, 1983).

O consórcio com caupi não diminuiu o desfolhamento causado por adultos de C. arcuata (Tabela 2). NAVA \& PARRA (2002) verificaram, em condições de laboratório, que adultos de $\boldsymbol{C}$. arcuatus têm preferência por folhas de soja, feijoeiro e abóbora em detrimento do caupi. RISH (1980) explica que, quando $\boldsymbol{C}$. ruficornis rogersi se alimenta em um consórcio formado por plantas hospedeiras, na ausência de uma cultura não-hospedeira, sua população aumenta significativamente em relação ao encontrado em uma das culturas ou em ambas, quando em situação de monocultura.
O tratamento com cobertura morta favoreceu aumentos significativos no peso de nódulos secos, número de nódulos inteiros (Tabela 1), peso de raiz e produção de grãos (Tabela 2). Como a infestação por adultos de $\boldsymbol{C}$. arcuata foi observada na emergência das plantas, aos 20 DAE já era intenso o ataque das larvas aos nódulos de feijoeiro nos tratamentos sem a cobertura morta (Tabela 1), devido ao curto período para a eclosão das larvas de C. arcuata, de aproximadamente sete dias (TEIXEIRA \& FRANCO, 2007). Dos 20 DAE até a floração, encontra-se o período crítico para a obtenção de nitrogênio através da simbiose do feijoeiro com o rizóbio. Como o inseto necessita de aproximadamente 26 dias para completar seu ciclo, aos 34 DAE, época da floração, foi registrado o pico populacional do inseto devido à emergência da 
Tabela 2 - Média e erro-padrão da infestação por $\boldsymbol{C}$. arcuata na área foliar, na matéria seca e no conteúdo total de nitrogênio da parte aérea de feijoeiro solteiro, com cobertura morta ou em consórcio com caupi ou milho. Médias das coletas aos 20, 27, 34 e 43 DAE $(n=16)$. Produtividade de grãos aos 70 DAE $(n=4)$

\begin{tabular}{|c|c|c|c|c|c|}
\hline Tratamentos & Área foliar ${ }^{1}$ & $\begin{array}{c}\text { Matéria seca parte } \\
\text { aérea }^{1}\end{array}$ & $\begin{array}{c}\mathrm{N} \text { total de parte } \\
\text { aérea }^{1}\end{array}$ & Matéria seca de raiz ${ }^{1}$ & $\begin{array}{l}\text { Produtividade } \\
\text { de grãos }^{1}\end{array}$ \\
\hline & $\mathrm{cm}^{2} \mathrm{pl}^{-1}$ & $\mathrm{~g} \mathrm{pl}^{-1}$ & $\mathrm{mgN} \mathrm{pl}^{-1}$ & $\mathrm{mg} \mathrm{pl}^{-1}$ & $\mathrm{~kg} \mathrm{ha}^{-1}$ \\
\hline Feijão solteiro & $1009,2 \pm 112,57 \mathrm{a}$ & $4,98 \pm 0,61 b$ & $174 \pm 20,75 a b$ & $542 \pm 55,67 \mathrm{ab}$ & $1138,75 \pm 78,15 b$ \\
\hline Cobertura morta & $1230,6 \pm 154,33 a$ & $6,22 \pm 0,76 a$ & $218 \pm 24,13 a$ & $700 \pm 93,86 a$ & $1590,7 \pm 107,5 \mathrm{a}$ \\
\hline Caupi consorciado & $909,2 \pm 103,63 \mathrm{a}$ & $4,49 \pm 0,54 b$ & $158+18,86 b$ & $501 \pm 46,48 b$ & $1078,8 \pm 139,4$ bc \\
\hline Milho consorciado & $956,2+111,14 \mathrm{a}$ & $4,40 \pm 0,67 b$ & $146+16,21 b$ & $482 \pm 67,69 b$ & $685,95 \pm 130,32 \mathrm{c}$ \\
\hline Média & $1019,5 \pm 10,28$ & $5,01 \pm 0,05$ & $174 \pm 1,9$ & $556 \pm 4,8$ & $1123,5 \pm 16,46$ \\
\hline CV (\%) & 32,28 & 34,57 & 35,02 & 28,13 & 23,45 \\
\hline
\end{tabular}

${ }^{1}$ Valores na mesma coluna não seguidos pela mesma letra diferem entre si pelo teste de Duncan em nível de 5\% de probabilidade de erro.

segunda geração de adultos (Tabela 1). Devido à infestação precoce pelo inseto e de seu ciclo curto, a época de maior dano aos nódulos coincidiu com a fase de maior requerimento de nitrogênio via simbiose, causando prejuízos através da redução da atividade da nitrogenase (Tabela 1) e do conteúdo de nitrogênio (Tabela 2), o que resultou na redução na produção de grãos (Tabela 2).

A barreira física imposta pela cobertura morta provavelmente dificultou a oviposição diretamente no solo, favorecendo o ressecamento dos ovos. A perda de umidade dos ovos é o fator limitante para a criação de $\boldsymbol{C}$. trifurcata, sendo que a eclosão diminui em condições extremas de umidade do solo (MARRONE \& STINNER, 1983). As larvas eclodidas sobre a palha descem em direção ao coleto e posteriormente às raízes do feijoeiro. $\mathrm{O}$ aumento da distância também pode ocasionar perdas, como no caso de larvas de Diabrotica virgifera virgifera LeConte, que têm seu número reduzido em $45 \%$ após 24 horas sem se alimentarem (BRANSON, 1989). ZEHNDER \& HOUGH-GOLDSTEIN (1989) verificaram que as quantidades de ovos, larvas e adultos do crisomelídeo $L$. decemlineata foram significativamente menores em parcelas de batata com cobertura de palha quando comparadas com parcelas sem cobertura. Resultado semelhante foi obtido por STONNER (1993), quando a cobertura de palha reduziu o número de larvas de $\mathbf{L}$. decemlineata em batata e também a porcentagem de coletos danificados, afetando a mortalidade ou o desenvolvimento dos ovos e das larvas. A porcentagem de nódulos furados do tratamento com cobertura morta foi significativamente inferior à dos demais tratamentos (Tabela 1). O número de insetos adultos no tratamento com cobertura morta acompanhou a tendência dos parâmetros de nodulação (Tabela 1 ), refletida no peso seco de parte aérea e na área foliar (Tabela 2). LAM \& PEDIGO (1998) verificaram que a população de $\boldsymbol{C}$. trifurcata em plantio direto de soja foi menor do que a registrada em cultivo mínimo. Devido ao ataque e à reprodução precoce de $\boldsymbol{C}$. arcuata, se a barreira imposta pela cobertura morta tivesse sido adicionada antes do plantio, ou o plantio efetuado na palha, provavelmente o controle das larvas teria sido mais efetivo, pois, imediatamente após a emergência das plantas, foram observadas folhas de feijão furadas.

Além da ação como barreira ao inseto, a cobertura morta proporciona outros benefícios para a cultura do feijão, agindo principalmente na retenção de umidade e diminuição de temperatura do solo. Rhizobium sp. é afetado em temperaturas acima de 35 C (HUNGRIA \& FRANCO, 1993). Entretanto, durante o experimento, houve uma variação de temperatura entre 20,2 e $25,5^{\circ} \mathrm{C}$. Uma vez que o experimento foi irrigado sempre que necessário e o feijoeiro foi inoculado com estirpes de rizóbio tolerantes a altas temperaturas, é provável que os benefícios da cobertura morta na produção de grãos tenham decorrido, em grande parte, da proteção contra as larvas de $\boldsymbol{C}$. arcuata. Proteção semelhante poderia ser obtida através do sistema de plantio direto sobre a palhada anterior, normalmente uma gramínea, ou através do uso de outras técnicas que formassem barreiras físicas para a larva do inseto, prejudicando seu acesso ao sistema radicular.

\section{CONCLUSÃO}

O consórcio com caupi ou com milho não teve efeito sobre os danos provocados pelo ataque de $\boldsymbol{C}$. arcuata em feijoeiro.

A aplicação da cobertura morta proporcionou uma redução nos danos provocados 
pelo ataque das larvas aos nódulos, favorecendo a fixação biológica de nitrogênio, o peso de raiz e a produção de grãos.

\section{AGRADECIMENTOS}

À CAPES e ao CNPq, pelo suporte financeiro durante a execução do trabalho. À Bruno Rezende Silva, pela revisão do abstract.

\section{REFERÊNCIAS}

ALTIERI, M.A. et al. O papel da biodiversidade no manejo de pragas. Ribeirão Preto: Holos, 2003. 226p.

ANDOW, D.A. Vegetational diversity and arthropod population response. Annual Review of Entomology, Palo Alto, v.35, p.561-586, 1991.

ANDOW, D.A. Population dynamics of an insect herbivore in simple and diverse habitats. Ecology, Ithaca, v.72, n.3, p.10061017, 1990.

AZEVEDO, F.R. de; ARAÚJO, E. Influência de diferentes arranjos de espaçamentos das culturas do milho e do feijão caupi sobre os danos causados por Spodoptera frugiperda (Smith) e a infestação de Cerotoma arcuata Oliv. e Empoasca kraemeri Ross \& Moore. Ciência Agronômica, Fortaleza, v.31, n.1-2, p.43-50, 2000.

BASTOS, C.S. et al. Incidência de insetos fitófagos e de predadores no milho e no feijão cultivados em sistema exclusivo e consorciado. Ciência Rural, Santa Maria, v.33, n.3, p.391-397, 2003.

BRANSON, T.F. Survival of starved neonate larvae of Diabrotica virgifera virgifera LeConte (Coleoptera: Chrysomelidae). Journal of Kansas Entomology Society, Lawrence, v.62, p.521-523, 1989.

BREMNER, J.M. Total nitrogen. In: BLACK, C.A. et al. (Eds.). Methods of soil analysis. Madison: American Society of Agronomy, 1965. p.1149-1178. (Agronomy, n.9).

BRUST, G.E. Natural enemies in straw-mulch reduce Colorado potato beetle populations and damage in potato. Biological Control, Orlando, v.4, n.2, p.163-169, 1994.

CARDONA, C. et al. Evaluation of damage to common beans by larvae and adults of Diabrotica balteata and Cerotoma facialis. Journal of Economic Entomology, Lanham, v.75, p.324-327, 1982.

COLL, M.; BOTTRELL, D.G. Predator-prey association in mono- and dicultures: effect of maize and bean vegetation. Agriculture, Ecosystems and Environment, Amsterdam, v.54, n.1-2, p.115-125, 1995.

FAZOLIN, M. Levantamento dos insetos e flutuação populacional das pragas que ocorrem na cultura do caupi (Vigna unguiculata (L.) Walp.) em Rio Branco (AC). Turrialba, San José, v.45, n.3-4, p.137-142, 1995.

FAZOLIN, M.; GOMES, T.C.A. Dinâmica populacional de Cerotoma tingomarianus Bechyné em caupi e puerária em Rio
Branco, Acre. Anais da Sociedade Entomológica do Brasil, Jaboticabal, v.22, p.491-495, 1993.

HARDY, R.D. et al. The acetylene-ethylene assay for $\mathrm{N}_{2}$ fixation: laboratory and field evaluation. Plant Physiology, Bethesda, v.43, p.1185-1207, 1968.

HOKKANEN, H.M.T. Trap cropping in pest management. Annual Review of Entomology, Palo Alto, v.36, p.119-138, 1991.

HUNGRIA, M.; FRANCO, A.A. Effects of hight temperature on nodulation and nitrogen fixation by Phaseolus vulgaris $\mathrm{L}$. Plant and Soil, The Hague, v.149, p.95-102, 1993.

JOHNSON, J.M. et al. Effects of straw mulch on pest insects, predators, and weeds in watermelons and potatoes. Environmental Entomology, Lanham, v.33, n.6, p.16321643, 2004.

LAM, W.K.F.; PEDIGO, L.P. Response of soybean insect communities to row width under crop-residue management systems. Environmental Entomology, Lanham, v.27, n.5, p.1069-1079, 1998.

LAYTON, B.M. The effects of feeding by bean leaf beetle larvae, Cerotoma trifurcata (Foster), on nodulation and nitrogen fixation of soybeans. 1983. 105f. Tese (Mestrado em Entomologia) - Curso de Pós-graduação em Entomologia, Louisiana State University.

MARRONE, P.G.; STINNER, R.E. Effects of soil physical factors on egg survival of the bean leaf beetle, Cerotoma trifurcata (Foster) (Coleoptera: Chrysomelidae). Environmental Entomology, Lanham, v.12, n.3, p.673-679, 1983.

MILANEZ, J.M. Estudo da entomofauna em consórcio de feijão-milho em Santa Catarina. Florianópolis: EMPASC, 1987. 16p. (EMPASC. Comunicado Técnico).

NAVA, D.E.; PARRA, J.R.P. Desenvolvimento de uma técnica de criação para Cerotoma arcuatus Olivier (Coleoptera: Chrysomelidae) em laboratório. Neotropical Entomology, Londrina, v.31, n.1, p.55-62, 2002.

QUinTelA, E.D. et al. Principais pragas do caupi no Brasil. Goiânia: Embrapa-CNPAF, 1991. 38p. (EmbrapaCNPAF. Documentos, 35).

RAMALHO, M.A.P. Consorciação milho-feijão. In: MAGNAVACA, R.; CASTANHEIRA, P.M. Cultura do milho. Brasília: EMBRATER, 1983. p.101-127.

RISCH, S. Effect of variety of cowpea (Vigna unguiculata L.) on feeding preferences of three chrysomelid beetles, Cerotoma ruficornis rogersi, Diabrotica balteata and Diabrotica adelpha. Turrialba, San José, v.26, p.327-330, 1976.

RISCH, S. The population dynamics of several herbivorous beetles in a tropical agroecosystem: the effect of intercropping corn, beans and squash in Costa Rica. Journal of Applied Ecology, Oxford, v.17, p.593-612, 1980.

SALAS, F.J.S et al. Tentativas de transmissão de um isolado do vírus do mosaico severo do caupi (CpSMV-SP) por artrópodos, 
em laboratório. Scientia Agrícola, Piracicaba, v.56, p.413420, 1999.

STONNER, K.A. Effects of straw and leaf mulches and trickle irrigation on the abundance of Colorado potato beetles (Coleoptera: Chrysomelidae) on potato in Connecticut. Journal of Entomological Science, Tifton, v.28, n.4, p.393403, 1993.

STRALIOTTO, R. et al. Cultivo do feijoeiro comum: fixação biológica de nitrogênio. Embrapa-Arroz e Feijão, 2003. Sistemas de Produção, 2. Acesso em: 11 de jul. 2006. Online. Disponível em: http://sistemasdeproducao.cnptia. embrapa.br/FontesHTML/Feijao/CultivodoFeijoeiro/ fbnitrogenio.htm.

TELLEZ-ROBLETO, J.; MAES, J.M. The use of multiple cropping of maize-kidney beans as an element of biological control against Dalbulus maidis (Homoptera: Cicadellidae). Revista Nicaraguense de Entomologia, Manágua, v.16, p.920, 1991.

TEIXEIRA, M.L.F. Efeito de Cerotoma arcuata Olivier (Coleoptera: Chrysomelidae) na fixação biológica de nitrogênio em feijoeiro (Phaseolus vulgaris L.). 1993. $176 f$. Tese (Mestrado em Ciência do Solo (Biologia do Solo)) - Curso de Pós-graduação em Agronomia, Universidade Federal Rural do Rio de Janeiro.
TEIXEIRA, M.L.F. et al. Effects of Cerotoma arcuata (Coleoptera: Chrysomelidae) on the predation of nodules and on $\mathrm{N}_{2}$-fixation of Phaseolus vulgaris. Journal of Economic Entomology, Lanham, v.89, n.1, p.165-169, 1996.

TEIXEIRA, M.L.F.; FRANCO, A.A. Susceptibilidade de larvas de Cerotoma arcuata Olivier (Coleoptera: Chrysomelidae) a Beauveria bassiana (Bals.) Vuillemin, Metarhizium anisopliae (Metsch.) Sorokin e Bacillus thuringiensis Berliner. Ciência Rural, Santa Maria, v.37, p.19-25, 2007.

TROXCLAIR, N.N.; BOETHEL, D.J. Influence of tillage practices and row spacing on soybean insect populations in Louisiana. Journal of Economic Entomology, Lanham, v.77, p.1571-1579, 1984.

YEPEZ-GIL, G.A.; AQUILES-MONTAGNE, A. Flight height of the bean leaf beetles Andrector arcuatus Olivier and $\boldsymbol{A}$. ruficornis Olivier (Coleoptera: Chrysomelidae) in a bean (Phaseolus vulgaris L.) field. Agronomia Tropical Maracay, Maracay, v.40, n.4-6, p.235-244, 1990.

ZEHNDER, G.W.; HOUGH-GOLDSTEIN, J. Colorado potato beetle (Coleoptera: Chrysomelidae) population development and effects on yield of potatos with and without straw mulch. Journal of Economic Entomology, Lanham, v.83, n.5, p.1982-1987, 1989. 